\title{
Contribuições das atividades experimentais para o despertar científico de alunos do ensino médio
}

Amanda Gabriele Rauber amanda.rauber@univates.br 0000-0002-5224-8476 Centro Universitário Univates - Lajeado, Rio Grande do Sul, Brasil.

\section{Marli Teresinha Quartieri}

mtquartieri@univates.br

Centro Universitário Univates - Lajeado,

Centro Universíáno Univate

\section{Maria Madalena Dullius}

madalena@univates.br

Centro Universitário Univates - Lajeado, Rio Grande do Sul, Brasil

\section{RESUMO}

Este trabalho visa socializar contribuições das atividades experimentais para despertar a curiosidade e a investigação pela área das Ciências Exatas. A pesquisa de abordagem qualitativa, caracterizada como um estudo de caso, foi realizada com quatorze estudantes do Ensino Médio, que, durante um ano, participaram de encontros científicos para a realização de atividades experimentais investigativas de Ciências. Eles também participaram do "Aprender Experimentando", evento em que orientavam e explicavam experimentos aos visitantes. A partir dos relatos dos integrantes e das filmagens de discussões semanais com o grupo, foi possivel perceber que as atividades experimentais Ihes despertaram o interesse, bem como possibilitaram a aquisição de novos conhecimentos sobre conteúdos de Física, Química e Matemática. As atividades estimularam a criatividade, o trabalho em grupo e o raciocínio lógico, oportunizando aos alunos estabelecerem conexões entre os elementos teóricos e práticos de cada conteúdo.

PALAVRAS-CHAVE: Ensino de Ciências. Experimentação. Formação de investigadores. 


\section{INTRODUÇÃO}

Em âmbito nacional, a experimentação no ensino de Ciências foi impulsionada a partir de 1960, marcada pela adaptação de diversos projetos norte-americanos, visando à formação de professores para a aplicação do método científico experimental (BARATIERI et al., 2008; BARCELOS et al., 2010). Porém, ao longo das décadas, as tendências pedagógicas continuaram sendo de cunho tradicional, especialmente no ensino das Ciências Exatas (Física, Química, Matemática), tencionando a mera transmissão do conhecimento científico mediante a apresentação de fórmulas e conceitos muitas vezes descontextualizados e vazios de significado para o aluno. A desconsideração pelo caráter de incentivo ao conhecimento científico que as Ciências Exatas têm apresentado pode constituirse em um grave entrave ao ensino e à aprendizagem de disciplinas dessa área, pois não propicia ao aluno o desejo e a capacidade de ampliar suas percepções acerca da realidade à sua volta e, portanto, não incentiva o espírito investigativo e o apreço pelas Ciências.

A experimentação pode ser uma aliada desse caráter de incentivo à investigação, podendo representar "[...] uma excelente ferramenta para que o aluno faça a experimentação do conteúdo e possa estabelecer a dinâmica e indissociável relação entre teoria e prática" (REGINALDO et al., 2012, p. 2). A respeito da experimentação no ensino de Ciências, Marques (1996, p. 40) defende que

[...] os aprendizados enriquecem a teoria e a prática, e as realimentam, ambas, uma da outra, fazendo com que a prática não seja apenas descrita e narrada, mas compreendida e explicada, melhor organizada e aprofundando os saberes que nutre ao deles nutrir-se. Dá-se, aprendizagem, nesses contextos de interação, pelo desenvolvimento das competências de relacionar, comparar, inferir, argumentar, mediante uma reestruturação mais compreensiva, coerente e aberta às complexidades das articulações entre as ideias, os dados, os fatos, as percepções e os conceitos.

De acordo com as ideias do referido autor, a experimentação tem o potencial de ser uma importante ferramenta de ensino e de aprendizagem, proporcionando aos alunos a possibilidade de estabelecer relações entre a teoria e a prática, incentivando-os a compreender os fenômenos que essas ciências abordam. Ademais, ela é proposta e discutida na literatura sob diversas abordagens em relação às características que pode apresentar em diversos contextos. Existe uma multiplicidade de possibilidades de utilização dessa estratégia no ensino das Ciências Exatas, com a faculdade de promover diferentes resultados aos discentes que têm contato com a experimentação.

Partindo desses pressupostos, surgiu a ideia da pesquisa "Formação de investigadores a partir de experimentos interativos", que explorou atividades de experimentação com alunos e professores do Ensino Médio, cujo objetivo foi incentivar a formação de investigadores e o apreço pelas Ciências. A pesquisa teve duração de um ano, ocorrendo entre 2014 e 2015, e contou com a participação de catorze alunos do Ensino Médio e duas professoras de Física, Química e Matemática da Educação Básica, bem como bolsistas de Iniciação Científica dos Cursos de Engenharia e professores-pesquisadores da Univates. Portanto, este artigo tem o objetivo de socializar as contribuições das atividades experimentais para despertar a curiosidade e a investigação pela área de Ciências Exatas. 


\section{OS ENCONTROS CIENTÍFICOS}

Ao longo de um ano, a equipe da pesquisa, formada por pesquisadores das áreas de Matemática, Física, Química, bem como bolsistas e estudantes de diversos cursos de graduação, realizou encontros quinzenais com alunos e docentes do Ensino Médio para realização e discussão de atividades, envolvendo experimentos interativos e aplicativos computacionais de Física, Química e Matemática. Intercaladas a esses encontros, eram realizadas reuniões com os professores da Educação Básica para discussões teóricas, avaliação do andamento da pesquisa e planejamento dos encontros com os discentes.

No primeiro encontro com alunos do Ensino Médio, foi aplicado um questionário, contendo perguntas que visavam conhecer as motivações que os levaram a participar do projeto, bem como os conhecimentos que possuíam acerca dos termos "experimentação", "ciência", e quais suas experiências com atividades experimentais e utilização do computador, como softwares, que normalmente utilizavam no seu dia a dia. Ato contínuo, discutiu-se em grupo o primeiro capítulo do livro "Iniciação Científica para Jovens Pesquisadores" (MENDES, 2012), que trata das diferenças entre a Ciência e a opinião, a fim de explicitar o trabalho científico, abordando assuntos como fontes, objetivos e formatos de um trabalho científico.

Diferente dos encontros posteriores, neste, os experimentos de Física, Química e Matemática explorados foram apresentados pelo grupo de pesquisa e tinham como objetivo desafiar os discentes sobre alguns conceitos, incentivandoos a investigar e buscar respostas por meio da experimentação. Assim, pela primeira vez, eles foram instigados a desenvolver experimentos que desejavam realizar a fim de sanar suas dúvidas e curiosidades, pois, de acordo com Zômpero e Laburú (2011), é essencial que "o problema a ser investigado seja escolhido em função dos interesses dos alunos. É necessário que os alunos se interessem pelo problema a ser investigado, de forma a existir motivação".

O cronograma utilizado nos demais encontros foi basicamente o mesmo: inicialmente, dos seis experimentos apresentados pelos discentes, realizavam-se apenas três, fato que deixava desapontados os que não tivessem os seus escolhidos. Diante desse contexto, decidiu-se, primeiramente, dividir os participantes em grupos menores, normalmente com dois alunos, dois bolsistas de iniciação científica da graduação e um professor, onde eram realizados os experimentos produzidos pelos integrantes do grupo.

Assim, cada participante defendia o seu experimento diante do grupo e, ao final do encontro, em consenso, este optava por um deles. Esse experimento escolhido era discutido e socializado com o grande grupo no início do encontro seguinte. Com isso, notou-se um aumento da participação dos alunos e um maior interesse em conhecer os experimentos dos colegas. Dessa forma, procurou-se apresentar os conceitos teóricos presentes nas atividades, relacionando-os com a prática e os fenômenos do cotidiano. Ao final, os alunos escreviam suas impressões e sentimentos sobre as atividades em um diário de campo, que foi utilizado como ferramenta de coleta de dados. Além disso, os encontros foram filmados mediante a autorização dos responsáveis dos alunos e, posteriormente, transcritos.

Página | 45

Nas Figuras 1, 2 e 3, estão expostos alguns experimentos discutidos nos pequenos grupos, relacionados às três disciplinas: 
Física (Figura 1)

- Caneca Assustada;

- Ponte Explosiva;

Figura 1 - Experimentos de Física propostos pelos alunos

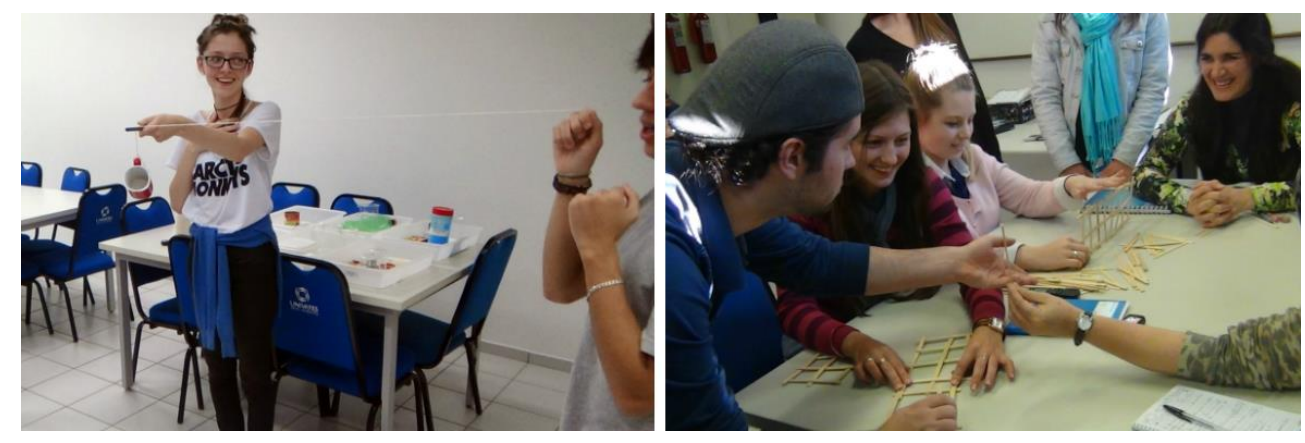

(Fonte: dos autores (2015))

Matemática (Figura 2)

- Desafios com Palitos (Matemática);

- Cilindro = Cone + Esfera $\div 2$ (Matemática);

Figura 2 - Experimentos de Matemática propostos pelos alunos

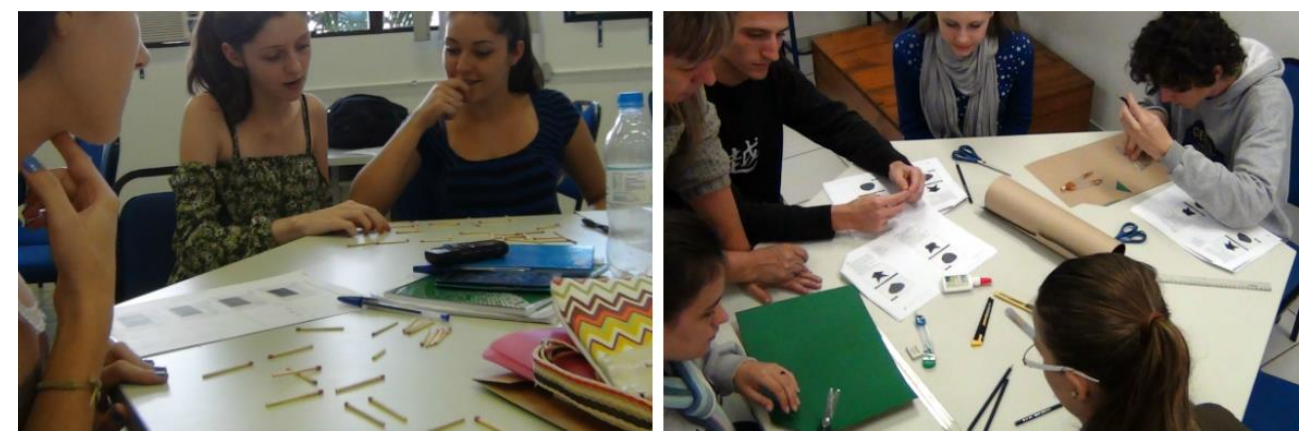

(Fonte: dos autores (2015))

Química (Figura 3)

- Leite Psicodélico (Química);

- Pasta de Dente de Elefante (Química); 
Figura 3 - Experimentos de Química propostos pelos alunos
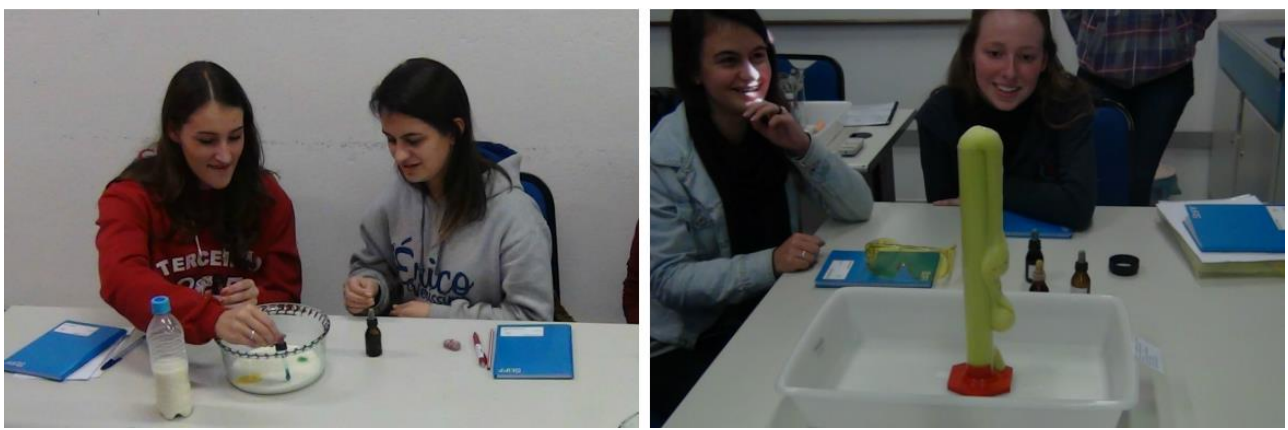

(Fonte: dos autores (2015))

Os integrantes também auxiliaram no desenvolvimento do "Aprender Experimentando", evento realizado na Univates e que contou com a participação de aproximadamente oitenta professores e mil e cinquenta alunos de vinte e quatro escolas. O objetivo, voltado aos anos finais do Ensino Fundamental e ao Ensino Médio, era apresentar experimentos de Física, Química e Matemática, possibilitando aos discentes manipularem, observarem, preverem, interpretarem e analisarem as atividades propostas. Coube aos bolsistas atuarem como orientadores de experimentos, além de realizá-los e explicá-los aos assistentes. Os experimentos trabalhados com os bolsistas durante os encontros científicos foram compilados em dois livros paradidáticos e distribuídos às escolas da região.

$\mathrm{Na}$ seção a seguir, estão expressos os dados procedentes dos alunos participantes da pesquisa com o intuito de identificar as contribuições das atividades experimentais por eles desenvolvidas para o ensino e a aprendizagem das Ciências Exatas. Salienta-se que a identificação dos bolsistas, na apresentação e análise dos dados, foi realizada por meio de letras e números, como $A 1, A 2$, e assim sucessivamente, visando preservar-Ihes o anonimato.

\section{DADOS EMERGENTES}

Com base nas filmagens e registros escritos dos encontros científicos e do Aprender Experimentando, destacam-se algumas declarações que denotam o envolvimento dos alunos com os referidos encontros. A primeira característica manifestada foi o despertar da atenção e motivação dos participantes. Segundo eles, a realização de experimentos estimulou-lhes o interesse, fato expresso nos excertos a seguir: principalmente nessas áreas envolvendo ciências exatas, pelo fato de as aulas serem muito teóricas e pela maior dificuldade nessas áreas (A1).

Nossos encontros são sempre muito interessantes, pois sempre aprendo mais com os experimentos e com os professores. É sempre bom aprender coisas novas e mostrar aos outros o que eu pesquisei e aprendi (A2).

[...] acredito que levando essas experiências à sala de aula, causará curiosidade aos estudantes e, de algum modo, os incentivará a pesquisar, ir atrás, melhorando seu desempenho escolar e descobrindo futuros (as), cientistas físicos, químicos, matemáticos, professores... (A3). 
É possível verificar que os próprios alunos conheciam o desinteresse existente nas salas de aula, realidade que a aluna A1 expressa em sua escrita. Ainda, segundo eles, o caráter motivador da experimentação ocorreu por ter sido diferente das aulas expositivas tradicionais, possibilitando a atenção dos discentes e incentivando-os à aprendizagem das Ciências. Entretanto, essa experimentação precisa ser abordada da maneira adequada, pois os diversos efeitos chamativos das atividades que a envolvem podem ou não atrair o discente para o fenômeno estudado, como explica Giordan (2006). É importante que seja feita uma observação crítica do tema apresentado, transformando a "curiosidade ingênua" em "curiosidade crítica" (GONÇALVES, MARQUES, 2006, p. 223).

Conforme os autores acima citados, para que a experimentação cumpra seu papel investigador, a atividade não deve se restringir ao seu elemento motivador de "show da ciência". Caso seja realizada sem uma análise crítica dos resultados, ela pode dificultar a aprendizagem conceitual (Ibidem, 2006). Portanto, atividades experimentais exploradas sob a perspectiva da investigação devem se adequar ao nível de compreensão do aluno a fim de permitir o entendimento e a construção do conceito envolvido, propiciando, dessa forma, um desenvolvimento cognitivo mais eficaz (ZULIANI et al., 2012).

Acerca do trabalho em pequenos grupos, algumas passagens expressam a importância do arranjo anteriormente mencionado para a realização de atividades experimentais:

A experiência que eu trouxe achei que não seria muito interessante fazer, pois era algo mais para se observar. Então escolhemos da A12, que era "Como ver sua própria voz". Assim, começamos a montar a dela, testamos e conversamos sobre como funcionava (A1).

Adorei fazer experiências, pois sempre gostei disso. Acho muito importante colocar em prática o que aprendemos, assim mexendo, pedindo, tirando dúvidas. Conhecer pessoas diferentes, de lugares diferentes, podendo compartilhar experiências, já que estamos aqui para aprender. Acho muito importante continuar esse projeto, pois fica mais interessante de aprender (A1).

Alguns materiais do meu experimento e o da A1 não tinha, então ajudamos a A12 a fazer o dela (como enxergar sua própria voz) (A2).

Portanto, o trabalho em pequenos grupos favorece a comunicação entre os alunos, a qual fortalece o respeito pelas opiniões diferentes, estabelece a negociação entre as ideias e ensina o discente a desconsiderar, por um momento, os seus objetivos pessoais (GALIAZZI \& GONÇALVES, 2004). Tal fato é perceptível nas passagens citadas anteriormente, pois, no primeiro caso, a aluna abdicou da realização de sua atividade em prol da colega. Em outra passagem, relata que essa técnica possibilitou a troca de experiências, que ela acreditava ser relevante.

Além disso, as atividades experimentais possuem potencial para enriquecer de diversas maneiras a criatividade dos alunos, conforme mostrado por Oliveira (2010): a partir da livre escolha dos experimentos que consideram interessantes Página | 48 através de substituições de materiais empregados nos experimentos, executando a montagem dos experimentos e até mesmo por meio de desenhos ou esquemas 
que representam a atividade experimental. Os trechos abaixo demonstram características relativas à criatividade:

Montei o jogo de uma forma mais simplificada usando apenas uma folha de papel e canetas coloridas para pintá-las (A1).

Ele era bem complicado de fazer então nós improvisamos e acabou dando certo (A2)

Em ambas as passagens, visando ao sucesso do experimento, os alunos improvisaram de maneira criativa fazendo uso da substituição de materiais, mas sem perder as características da atividade. Outro fato importante que é perceptível nesses trechos é a iniciativa pessoal, considerada fundamental por diversos autores (OLIVEIRA, 2010; GALIAZZI \& GONÇALVES, 2004). Segundo eles, as atividades experimentais proporcionam situações em que são necessárias a tomada de decisão e a iniciativa pessoal, capazes de fornecer bases sociais para o desenvolvimento do estudante, fornecendo suporte para o enfrentamento de situações novas que exijam tais atitudes dentro e fora da sala de aula.

As atividades experimentais também podem proporcionar ao aluno o desenvolvimento de seu raciocínio lógico, exigindo que ele consiga interligar informações teóricas com os fenômenos observados na atividade experimental e, a partir disso, estabelecer hipóteses sobre os resultados da experimentação (OLIVEIRA, 2010). Os fragmentos abaixo mostram relatos de situações em que os participantes elaboraram hipóteses:

\footnotetext{
Não achei nada que se referia o que interferia na velocidade do crescimento. Então, deduzi que o que interferia era o bicarbonato de sódio, pois, quando era queimado, se transformava em água e gás carbônico. Assim, o gás criava bolhas que faziam com que o experimento ficasse cada vez maior (A1).

O experimento não funcionou, o motivo não sabemos, pois construímos certo. Achamos que talvez seja por causa dos pesos ou as diferenças de massa (A3).

Surgiram muitas questões sobre o experimento de química, foi bem interessante (A5).
}

A insatisfação de $\mathrm{A} 1$ com os resultados do experimento que realizou foi evidente. Nesse sentido, ela resolveu pesquisar mais detalhadamente sobre o assunto e, juntamente com as explicações dos professores, elaborou uma hipótese para as causas de tal fenômeno. No segundo fragmento, o experimento do grupo não funcionou, e os alunos citaram, a partir de seus conhecimentos, motivos para o insucesso da prática. Percebe-se que as atividades experimentais exigiram, dos estudantes, discussões de ideias, elaboração de hipóteses explicativas e argumentativas, constituindo-se, de acordo com Bassoli (2014), em atividades de experimentação investigativa. A autora defende que esse tipo de atividade estimula a interatividade intelectual, física e social dos discentes, contribuindo para a formação de conceitos.

O evento Aprender Experimentando proporcionou aos participantes a oportunidade de socializarem seus conhecimentos com outros alunos por meio da Página | 49 realização de experimentos de Ciências. Nos relatos, eles expressam o seu envolvimento com as atividades. 
Hoje foi muito legal, me surpreendi comigo mesma. Expliquei para várias turmas de diferentes escolas tudo sobre o jogo. No início eu fiquei nervosa, claro, mas, no final, foi satisfatório (A6).

Foi minha primeira experiência, foi muito difícil para mim no começo, pois sou um pouco tímida, mas, depois de um tempo, tudo passa, e comecei a me familiarizar com o experimento da pasta de dente de elefante (A7).

[...] no início, estava com um pouco de vergonha de me apresentar para outras pessoas, mas depois fui me soltando, assim como aprendi maneiras mais fáceis de explicar para as pessoas no final. No começo, estava explicando de maneira mais científica, mas, no final, já estava explicando só o mais importante, para as pessoas entenderem (A12).

Foi uma experiência bem diferente, pois eu estava com um pouco de vergonha e medo de não dar conta. Mas depois de entender bem o experimento, tive confiança de repassar para as pessoas. Era muito bom quando as pessoas faziam perguntas, pois isso mostrava que estavam interessadas e acabavam me deixando feliz (A13).

Os relatos mostram que, no decorrer das atividades, os alunos adquiriram maior segurança para realizar e explicar os experimentos. Por conduzirem repetidas vezes a mesma atividade, declararam que conseguiram compreender melhor o fenômeno e, assim, ampliar seus conhecimentos. $O$ desenvolvimento do conhecimento científico do discente acontece quando ele consegue estender suas ideias como consequência da manipulação e interação com os objetos (REGINALDO et al., 2012). Em razão de terem entendido mais detalhadamente o que estavam explicando, os participantes foram modificando a maneira de se expressar, levando os visitantes a compreenderem melhor o experimento.

O fragmento que segue é um relato da percepção de uma aluna acerca de sua capacidade de ensinar e da participação dos alunos visitantes:

\begin{abstract}
As atividades realizadas no aprender experimentando me proporcionaram um aprendizado diferente, proveniente do convívio com alunos de diferentes lugares, idades e conhecimentos. A cada realização da experiência, era possível ver o entusiasmo e a curiosidade despertar. Por inúmeras vezes, ouvi os alunos querendo saber o porquê do acontecimento e tendo a vontade de fazer o experimento em casa ou na escola em feiras. Foi muito gratificante poder ver o quão importante é transmitir conhecimento e ver como isto realiza e encanta diversas pessoas (A8).
\end{abstract}

Para a nomeada aluna, sair de uma postura passiva e passar a explicar os fenômenos envolvidos em um experimento para outras pessoas foi uma experiência gratificante. É importante destacar que a demonstração de interesse por parte dos discentes visitantes foi essencial para que isso ocorresse. Os questionamentos por eles apresentados e as discussões efetivadas estabeleceram a interatividade intelectual, física e social, considerada, segundo Bassoli (2014), importante para a formação de conceitos. Além disso, a adoção de uma postura ativa por parte dos estudantes na realização de experimentos investigativos é uma forma de levá-los a participar de seu processo de aprendizagem (REGINALDO et al., 2012). 


\section{CONSIDERAÇÕES FINAIS}

Ao participarem da pesquisa, os alunos do Ensino Médio tiveram a oportunidade de adquirir novos conhecimentos por meio das atividades experimentais investigativas. Em seus relatos, identifica-se a relevância destas, que Ihes possibilitaram manipular, observar, prever, interpretar, investigar e analisar, tornando-os formadores de sua aprendizagem. A experimentação possui caráter motivador, mas é importante preservar as características investigativas de sua utilização para que aconteça a construção efetiva dos conceitos envolvidos na atividade.

Aliada a tais questões, a experimentação, quando realizada em pequenos grupos, pode fomentar a investigação por parte dos estudantes. 0 trabalho em grupo favorece as discussões produtivas e estabelece o respeito entre ideias diferentes. Tais fatores são importantes para que o discente aprenda a conviver, tanto fora como no interior da sala de aula, de maneira saudável. Ademais, as discussões incentivam o pensamento crítico, a argumentação e a formação de hipóteses, elementos considerados relevantes para a construção do conhecimento do aluno.

A realização do evento Aprender Experimentando, além de oportunizar a centenas de alunos a oportunidade de observar, manipular e interagir com diversos experimentos de Física, Química e Matemática, proporcionou aos quatorze participantes do projeto a oportunidade de se envolverem ainda mais com as atividades de experimentação. Ao serem constantemente questionados pelos visitantes, foram instigados a refletir sobre os conteúdos envolvidos nos experimentos, conduzindo-os à crença de que foram construindo seu próprio conhecimento.

Assim, pode-se concluir que as atividades realizadas, ao longo desta pesquisa, aguçaram o interesse dos participantes pelas Ciências Exatas, bem como possibilitaram a construção de diversos conhecimentos sobre conteúdos de Física, Química e Matemática. A experimentação investigativa estimulou a criatividade, o trabalho em grupo e o raciocínio lógico dos discentes por meio da manipulação, observação, análise e formulação de hipóteses, levando-os a estabelecer conexões entre os elementos teóricos e práticos de cada conteúdo. Com isso, acredita-se ter contribuído para a formação de alunos investigadores, formadores ativos de seu próprio conhecimento. 


\title{
Contributions from experimental activities for scientific awakening of high school students
}

\begin{abstract}
This work aims to socialize the contributions of experimental activities to arouse curiosity and research the area of Exact Sciences. The qualitative research, featured as a study case, was conducted with fourteen High School students, which during one year participated in scientific meetings for performing experimental and investigative Science activities. The students also participated in the event "Aprender Experimentando", where they oriented and explained experiment for visitors. From the written records of the participants, and from the filming of weekly discussions with the student group, it was possible to notice that the experimental activities aroused the interest of them as well as have enabled the acquisition of new knowledge about Physics, Chemistry and Mathematics. The activities stimulates creativity, teamwork and logical reasoning, enabling students to establish connections between the theoretical and practical elements of which content.
\end{abstract}

KEYWORDS: Science education, Experimentation, Researchers education. 


\section{AGRADECIMENTOS}

Agradecemos à Fundação de Amparo à Pesquisa do Estado do Rio Grande do Sul, ao Conselho Nacional de Desenvolvimento Científico e Tecnológico e ao Centro Universitário Univates, pelo auxílio na realização da pesquisa e do Evento Aprender Experimentando.

\section{REFERÊNCIAS}

BARATIERI, S. M.; BASSO, N. R. S.; BORGES, R. M. R.; FILHO, J. B. R. Opinião dos estudantes sobre a experimentação em química no ensino médio. Experiências em Ensino de Ciências, Cuiabá, v. 3, p. 19-31, 2008.

BARCELOS, N. N. S.; JACOBUCCI, G. B.; JACOBUCCI, D. F. C. Quando o cotidiano pede espaço na escola, o projeto da feira de ciências "Vida em Sociedade" se concretiza. Ciência \& Educação, Bauru, v. 16, n. 1, p. 215-233, 2010.

BASSOLI, F. Atividades práticas e o ensino-aprendizagem de ciência(s): mitos, tendências e distorções. Ciência \& Educação, Bauru, v. 20, n. 3, p. 579-593, 2014.

GALIAZZI, M. C.; GONÇALVES, F. P. A natureza pedagógica da experimentação: uma pesquisa na licenciatura em Química. Química Nova, São Paulo, v.27, n.2, p.326-331, 2004.

GIORDAN, M. O papel da experimentação no ensino de ciências. Química Nova na Escola, São Paulo, n.10, p.43-49, 1999.

GONÇALVES, F. P.; MARQUES, C. A. Contribuições pedagógicas e epistemológicas em textos de experimentação no ensino de química. Investigações em Ensino de Ciências, Porto Alegre, v. 11, n. 2, p. 219-238, 2006.

MARQUES, M. O. Educação/interlocução: aprendizagem/reconstrução de saberes. Ijuí: UNIJUÍ, 1999.

MENDES, F. R. Iniciação Científica para jovens pesquisadores. Porto Alegre: Autonomia Editora, 2012.

OLIVEIRA, J. R. S. Contribuições e abordagens das atividades experimentais no ensino de ciências: reunindo elementos para a prática docente. Acta Scientiae, Canoas, v. 12, n. 1, p. 139-153, jan./jun. 2010. 
REGINALDO, C. C.; SHEID, N. J.; GÜLLICH, R. I. C. O ensino de ciências e a experimentação. In: SEMINÁRIO DE PESQUISA EM EDUCAÇÃO DA REGIÃO SUL, 9., Caxias do Sul. Anais... Caxias do Sul: UCS, 2012. Disponível em:

<http://www.portalanpedsul.com.br/admin/uploads/2012/Ensino_de_Matemati ca_e_ciencias/Trabalho/12_52_37_2782-6658-1-PB.pdf>. Acesso em: 04 jul. 2016.

ZÔMPERO, A. F.; LABURÚ, C. E. Atividades Investigativas no ensino de ciências: aspectos históricos e diferentes abordagens. Revista Ensaio, Belo Horizonte, v. 13, n. 3, p. 67-80, set./dez. 2011.

ZULIANI, S. R. Q. A.; BOCANEGRA, C. H.; GAZOLA, R. J. C.; MARTINS, D. S.; MELLO, D. F. O experimento investigativo e representações de alunos de ensino médio: obstáculos epistemológicos em questão. Educação: teoria e prática, Rio Claro, v. 22, n. 40, p. 100-113. Rio Claro: mai./ago. 2012.

DOI: $10.3895 /$ rbect.v10n1.5717

Como citar: RAUBER, A. G.; QUARTIERI, M. T.; DULLIUS, M. M. Contribuições das atividades experimentais para o despertar científico de alunos do ensino médio. Revista Brasileira de Ensino de Ciência e Tecnologia, v. 10, n. 1, 2017. Disponível em:

<https://revistas.utfpr.edu.br/rbect/article/view/5717>. Acesso em: xxx.

Direito autoral: Este artigo está licenciado sob os termos da Licença Creative Commons-Atribuição 4.0 Internacional.

\section{(c) (1)}

